\title{
Özel Güvenlik Personellerinin Covid-19 Kaygı Düzeylerinin Covid-19 Geçmişlerine ve Demografik Özelliklerine Göre İncelenmesi*
}

\author{
Investigation of The Covid-19 Anxiety Levels of Private Security Guards According to Their Covid-19 \\ Background and Demographic Characteristics
}

\author{
Ömer Faruk Coşkun**1(D) Ali Bedir ${ }^{1}$ (D)
}

${ }^{1}$ Antakya Vocational School, Hatay Mustafa Kemal University, Hatay, Turkey

\begin{abstract}
Received: 12.06 .2021
Accepted: 30.07 .2021

This article was checked by intihal.net

Öz

Bu çalışmanın amacı; özel güvenlik personellerinin Covid-19 kaygı düzeyinin Covid-19 geçmişlerine ve demografik özelliklerine göre farklılaşıp farklılaşmadığını tespit etmektir. Bu amaç doğrultusunda, Hatay ilinde aktif olarak görev yapan özel güvenlik personelleri araştırmanın evreni olarak belirlenmiş olup, 125 özel güvenlik personelinden çevrimiçi anket tekniği kullanılarak veriler toplanmıştır.

Bu araştırmada, Covid-19 kaygı düzeyinde cinsiyete, medeni duruma ve daha önce kişiye Covid-19 tanısı konulup konulmadığına göre anlamlı bir farklılık olduğu sonucuna ulaşılmıştır. Araştırma sonuçları kadın özel güvenlik personellerinin Covid-19 kaygı düzeyinin erkek özel güvenlik personellerine göre daha yüksek olduğunu göstermektedir. Ayrıca analiz sonuçlarında, evli özel güvenlik personellerinin Covid-19 kaygı düzeyinin bekâr özel güvenlik personellerine göre daha yüksek olduğu görülmektedir. Bununla birlikte araştırma sonuçları daha önce kendisine Covid-19 tanısı konan özel güvenlik personellerinin daha önce kendisine Covid-19 tanısı konmayan özel güvenlik personellerine göre Covid-19 kaygı düzeyinin daha yüksek olduğunu ortaya koymaktadır. Diğer taraftan özel güvenlik personellerinin daha önce Covid-19 testi yaptırıp yaptırmamasına, daha önce bir tanıdığına veya yakınına Covid-19 tanısı konulup konulmamasına ve daha önce bir tanıdığını veya yakınını Covid19 nedeni ile kaybedip kaybetmemesine göre Covid-19 kaygı düzeylerinde anlamlı bir farklılık olmadığı tespit edilmiştir. Bu çalışmanın özel güvenlik personellerinin Covid-19 kaygı düzeyini inceleyen ilk araştırma olması, çalışmaya özgünlük kazandırmaktadır.
\end{abstract}

Anahtar Kelimeler: Covid-19, Kaygı, Korku, Özel Güvenlik, Covid-19 Geçmişi

\section{Abstract}

The aim of this study; it is to determine whether the Covid-19 anxiety level of private security guards differs according to their Covid-19 background and demographic characteristics. For this purpose, private security guards who work actively in the province of Hatay were determined as the universe of the research and data were collected from 125 guards by online survey technique.

In this study, it was concluded that there is a significant difference in the level of Covid-19 anxiety according to gender, marital status and whether the person has been diagnosed with Covid-19 before. The results of the research show that the Covid-19 anxiety level of females are higher than males. Besides, the analysis results show that married guards have a higher Covid-19 anxiety level than single guards. In addition, the results of the research reveal that the level of Covid-19 anxiety is higher for guards who have been diagnosed with Covid-19, compared to guards who have not been. On the other hand, it has been determined that there is no significant difference in Covid-19 anxiety levels, depending on whether guards have had a Covid-19 test, their relative has been diagnosed with Covid-19, and they have lost a relative due to Covid-19. This study is the first to examine the Covid-19 anxiety level of private security guards. This gives originality to this study.

Keywords: Covid-19, Anxiety, Fear, Private Security, Covid-19 Background

Coşkun, Ö.F. \& Bedir, A. (2021). "Özel Güvenlik Personellerinin Covid-19 Kaygı Düzeylerinin Covid-19 Geçmişlerine ve Demografik Özelliklerine Göre Incelenmesi", Journal of Academic Value Studies, 7(2), 146-156 (http://dx.doi.org/10.29228/javs.51751).

\footnotetext{
*Bu çalışma 2. Uluslararası İktisadi ve İdari Bilimler Kongresi’nde sunulan “Özel Güvenlik Personellerinin Covid-19 Kaygı Düzeylerinin Covid-19 Geçmişlerine ve Demografik Özelliklerine Göre İncelenmesi” başlıklı özet bildirinin genişletilmiş halidir. **E-mail address: farukcosk@gmail.com (Corresponding author)
} 


\section{Giriş}

2019 yııının sonlarında Çin'in Wuhan şehrinde ortaya çıkarak tüm dünyayı etkisi altına alan Covid-19 pandemisi, 2020 yılı itibari ile dünyanın en önemli gündem maddesi haline gelmiştir. 31.05.2021 tarihi itibari ile Dünya Sağlık Örgütü tarafından vaka sayısının 170.000 .000 ve vefat sayısının 3.500.000 üzerinde olduğu ifade edilmektedir (WHO, 2021). Türkiye'de ise Sağık Bakanlığı'nın açıkladığı verilere göre, vaka sayısı 5.200.000'i vefat sayısı 47.500'ü geçmiştir (SB, 2021). Covid-19 pandemisi, toplumun her kesiminin hayatında sosyokültürel, teknolojik ve ekonomik olarak köklü değişimlere neden olmuştur. Bu değişimden en çok etkilenen alanların başında ise iş dünyası gelmektedir.

Bu dönemde iş dünyasında tüm çalışanlar Covid-19 pandemisinden az veya çok etkilenmiş olsa da bazı meslek grupları diğerlerine oranla çok daha büyük bir risk ve tehlike altında çalışmakla birlikte Covid-19 pandemisinin neden olduğu değişimden fiziksel ve psikolojik olarak daha fazla etkilenmektedir. Bu meslek gruplarının başında ise özel güvenlik personelleri gelmektedir. İngiltere Ulusal istatistik Ofisinin 9 Mart-25 Mayıs arasında Covid-19 nedeni ile hayatını kaybeden bireyler üzerinde İngiltere'de ve Galler'de yapmış olduğu çalışma sonuçları bu durumu gözler önüne sermektedir. Bu çalışmada, İngiltere'de güvenlik personellerinin hastalığa karşı en savunmasız grup olduğu ve hastalık nedeni ile tüm meslekler arasında en yüksek ölüm oranın (her 100.000 erkekten 74'ü) özel güvenlik görevlilerinde olduğu belirtilmektedir (Sabah, 2021). Bu örnekte görüldüğü üzere özel güvenlik personelleri, hastalığa yakalanmış veya taşıyıcı olma ihtimali yüksek bireyler ile sürekli fiziksel iletişim halinde çalıştıkları için toplumun diğer kesimlerine kıyasla daha fazla risk ve tehlike altındadır. Bu riskli ve tehlikeli çalışma ortamı özel güvenlik personellerinin stres ve kaygı yaşama potansiyelini arttırmaktadır. Aynı zamanda özel güvenlik personelleri Covid-19 pandemisi sürecinde farkı nedenler ile psikolojik olarak yıpranmaktadır. Bu yıpranma kimi zaman turizm sektöründe olduğu gibi işlerini kaybetme korkusundan, kimi zamanda sağlık sektöründe olduğu gibi sorumluluklarının artmasından kaynaklanmaktadır (Uçkun ve Uçkun, 2020: 191).

Çalışanların hastalığa yakalanma korkusu, sağlık kuruluşlarının kapasite yetersizliği dolayısı ile tedavi olamama korkusu ve hastalığı aile ve çevresine bulaştırma endişesi kaynaklı olarak ortaya çıkan Covid-19 kaygısının tüm çalışanlarda olduğu gibi özel güvenlik personelleri üzerinde de farklı psikolojik etkileri olabilmektedir. Diğer taraftan Covid-19 kaygısı nedeni ile özel güvenlik personelleri ellerinden gelenin en iyisini yapmak için motivasyona sahip olmadığı için iş performanslarında yaşanan düşüş örgütlerde çok büyük maliyetlere yol açabilmektedir. Ayrıca Covid-19 kaygısının tetikleyeceği olumsuz durumlar, özel güvenlik hizmetinin etkin ve verimli şekilde sunulmasında ciddi bir tehlike olarak karşımıza çıkabilmektedir.

Çalışanların Covid-19 kaygı düzeyini tespit etmek için özellikle sağlık hizmetlerinde görev yapan bireylere yönelik geçmiş dönemde birçok çalışma (Dinibutun, 2020; Yüncü ve Yılan, 2020; Akalın ve Modanlıoğlu, 2021; Arpacıoğlu vd., 2021) yapılmış olmasına rağmen sağlık çalışanları kadar risk ve stres altında görevlerini yürüten özel güvenlik personellerine yönelik alan yazında bir çalışmaya rastlanmamıştır. Bu çalışmanın bu boşluğu doldurarak Covid-19 pandemisi sürecinde özel güvenlik personellerinin Covid-19 kaygı düzeyinin hangi seviyede olduğunun ortaya konmasına yardımcı olacağı düşünülmektedir. Diğer taraftan sağlık çalışanları dışında farklı bir meslek grubunda yapılan bu çalışmanın Covid-19 kaygısına yönelik sonuçların genelleştirilmesine katkıda bulunması beklenmektedir. Bu çalışmanın özel güvenlik personellerinin Covid-19 kaygı düzeyini inceleyen ilk araştırma olması, çalışmaya özgünlük kazandırmaktadır.

\section{Kavramsal Çerçeve}

"Genellikle kötü bir şey olacakmış düşüncesiyle ortaya çıkan ve sebebi bilinmeyen gerginlik duygusu" olarak tanımlanan kaygı (TDK, 2021), Covid-19 pandemisi süreci ile birlikte günümüzde artık daha sık karşılaşılan bir kavramdır. Bireylerin enfekte olma, sağlık kurumlarının yetersizliği nedeni ile tedavi olamama ve çevresindeki insanlara hastalığı bulaştırma gibi korkularından kaynaklanan Covid-19 kaygısı salgın döneminde insanlar üzerinde önemli psikolojik etkilere neden olmaktadır. (Altun, 2020: 313). Yapılan çalışmalar Covid-19 kaygısının depresyon, anksiyete, panik atak ve travma sonrası stres bozukluğu (Ho vd., 2020) gibi rahatsızlıklara yol açarak insanların ruh sağlığını olumsuz olarak etkilediğini göstermektedir (Ahmed vd., 2020; Moccia vd., 2020; Wang vd., 2020). Birçok araştırma çalışanların Covid-19 kaygısındaki artışın tükenmişlik düzeylerini arttıracağını ortaya koymaktadır. Akbaba ve Bulut (2021) tarafından muhasebe meslek mensuplarının Covid-19 pandemisi sürecinde tükenmişlik düzeylerini belirlemeye yönelik yapılan araştırmada, 
çalışanların Covid-19 pandemisi sürecinde tükenmişlik düzeylerinin yüksek olduğu tespit edilmiştir. Arpacıoğlu vd., (2021) tarafından sağlık çalışanlarının Covid-19 kaygısı ile tükenmişlik düzeyleri arasındaki ilişkinin incelendiği çalışmada, tükenmişlik ile Covid-19 kaygısı arasında pozitif yönlü anlamlı bir ilişki olduğu sonucuna ulaşılmıştır.

Covid-19 kaygısı insan odaklı mesleklerde daha fazla karşılaşılan ve iş nedeni ile insanlar ile çok fazla fiziksel iletişimde olan bireylerde daha sık görülen bir durumdur (Akbaba ve Bulut, 2021: 38). Hastaneler, eğitim kurumları, turizm işletmeleri, terminaller ve hava limanları gibi birçok farklı sektörde görev alan özel güvenlik personelleri de insan odaklı şekilde toplumsal yaşamın tam merkezinde çalışmaktadır (Uçkun ve Uçkun, 2020: 190). Özel güvenlik personellerinin bağlı oldukları 5188 sayılı Kanunda yer alan görev ve sorumlulukları incelendiğinde, iş sorumluluklarının yüksek olduğu görülmektedir (Ersezgin ve Tok, 2018: 19-20). Çalışma ortamı ve şartları gereği zaten stresli ve riskli bir durumda görevlerini yürüten özel güvenlik personellerinin Covid-19 pandemisi sürecinde görev ve sorumlulukları her geçen gün daha fazla genişletilmektedir. Özel güvenlik personelleri görev aldıkları kurumların güvenliğini sağlamanın yanında Covid-19 tedbirlerinin sağlıklı şekilde uygulanması konusunda aktif rol oynamaktadır. Covid-19 pandemisi sürecinde kendilerine hastalığın bulaşmasına yönelik kaygılarının yanında kimi zaman tedbirlere uymayan veya direnç gösteren insanların fiziki ve psikolojik saldırılarına (Sputniknews, 2020; Cnnturk, 2020) maruz kalmaları özel güvenlik personellerinin psikolojilerini yıpranmaktadır. Bu nedenle özel güvenlik personellerinin çalışma şartları ve çalışma ortamı göz önünde bulundurulduğunda, bu çalışanların Covid-19 kaygı düzeyinde artış olma ihtimali bulunmaktadır.

Bu bağlamda, özel güvenlik personellerinin Covid-19 kaygı düzeylerini etkileyen unsurların neler olduğunu belirlemek, hem bireylerin psikolojik ve fizyolojik sağlıklarının korunması hem de olumlu bir örgüt ikliminin oluşturulması için büyük önem arz etmektedir. Bu nedenle "Covid-19 kaygısını etkileyen demografik özellikler nelerdir?" ve "Covid-19 kaygısını bireylerin Covid-19 geçmişleri nasıl şekillendirmektedir?" soruları cevaplanması gereken iki önemli soru olarak karşımıza çıkmaktadır. Bu sorulara cevap bulmak amacı ile özel güvenlik personellerinin Covid-19 kaygı düzeylerinin Covid-19 geçmişlerine ve demografik özelliklerine göre farklılaşıp farklılaşmadığını tespit etmek için aşağıda yer alan hipotezler oluşturulmuştur.

\section{H1. Özel güvenlik personellerinin Covid-19 kaygı düzeyi cinsiyete göre farklılaşmaktadır.}

H2. Özel güvenlik personellerinin Covid-19 kaygı düzeyi medeni duruma göre farklılaşmaktadır.

H3. Özel güvenlik personellerinin Covid-19 kaygı düzeyi daha önce Covid-19 testi yaptırıp yaptırmadığına göre farklılaşmaktadır

H4. Özel güvenlik personellerinin Covid-19 kaygı düzeyi daha önce kendilerine Covid-19 tanısı konup konmadığına göre farklılaşmaktadır.

H5. Özel güvenlik personellerinin Covid-19 kaygı düzeyi yakınlarına veya tanıdıklarına Covid-19 tanısı konup konmadığına göre farklılaşmaktadır.

H6. Özel güvenlik personellerinin Covid-19 kaygı düzeyi yakınlarını veya tanıdıklarını Covid-19 nedeni ile kaybedip kaybetmediklerine göre farklılaşmaktadır.

\section{Yöntem}

Bu araştırmanın amacl; Covid-19 pandemisi sürecinde yüksek risk ve tehlike altında çalışan meslek gruplarından biri olan özel güvenlik personellerinin Covid-19 kaygı düzeyinin Covid-19 geçmişlerine ve demografik özelliklerine göre farklılaşıp farklılaşmadığını tespit etmektir. Bu amaç doğrultusunda, Hatay ilinde aktif olarak görev yapan özel güvenlik personelleri araştırmanın evreni olarak belirlenmiştir. Kolayda örneklem yöntemi ile seçilen 125 kişi araştırmanın örneklemini oluşturmaktadır.

Araştırmada veri toplama yöntemi olarak çevrimiçi anket tekniği kullanılmış olup, uygulama katıımcılarına anket formları yazışma uygulamaları ve elektronik posta yolu ile ulaştırılıışır. Katııımcılardan gönüllülük esasına uygun olarak anket formlarını içtenlikle doldurmaları istenmiştir. Anket formu; giriş ve iki bölümden oluşmaktadır. Giriş bölümünde, araştırmanın amacı, kapsamı, niteliği ile ilgili bilgi metni yer almaktadır. Birinci bölümde, "cinsiyet" ve "medeni durum" olmak üzere kişisel bilgilere yönelik kapalı uçlu sorular ile "Covid-19 testi yaptırdınız mı?", "Covid-19 tanısı daha önce size kondu mu? ", "Covid-19 tanısı konan bir tanıdığınız/yakınınız oldu mu?" ve "Covid-19 nedeni ile bir yakınınızı/tanıdığınızı kaybettiniz mi?" şeklinde 
ifadelerin yer aldığı Covid-19 geçmişlerine yönelik "Evet" veya "Hayır" olarak cevaplanan sorular bulunmaktadır. İkinci bölümde ise, Ahorsu vd. (2020) tarafından geliştirilen ve Ladikli vd. (2020) tarafından Türkçe güvenirlik ve geçerlilik çalışması yapılan "Covid-19 Korku Ölçeği" yer almaktadır. "Covid-19 Korku Ölçeği" katılımcıların Covid-19 kaygısını ölçmek amacı ile 7 ifadeden oluşmaktadır. Bu ölçek; "kesinlikle katılmıyorum", "katılmıyorum", "ne katılıorum ne katımıyorum", "katılmıyorum" ve "kesinlikle katılıyorum" olmak üzere $5^{\prime}$ li likert şeklinde derecelendirilmektedir.

Covid-19 Korku Ölçeğinin geçerliliğini ve güvenirliğini değerlendirmek amacı ile Cornbach Alfa değeri hesaplanmış faktör analizi yapılmıştır. Covid-19 Korku Ölçeğinin Kaiser-Meyer-Olkin değeri= 0,891 ve Bartlett Testi değeri= 629,90 ( $p<.001$ ) olarak tespit edilmiştir. KMO değeri 0,80'den büyük olduğu için örneklemden elde edilen veriler yeterlidir. Bartlett Testi sonucu 0.05 den küçük olduğu için ölçekteki ifadeler arasındaki ilişki faktör analizi için uygundur. Ayrıca ölçekteki ifadeler tek faktör altında toplanmakta olup, toplam varyansın \% 68,72'ini açıklamaktadır. Covid-19 Korku Ölçeğinde yer alan 7 ifadenin faktör yükleri Tablo 1'de gösterilmektedir.

Özel güvenlik personellerinin Covid-19 kaygı düzeyini belirlemeye yönelik olarak kullanılan Covid-19 Korku Ölçeğinin iç tutarlıı̆̆ını belirlemek için Cronbach's Alfa testi yapılmıştır. Elde edilen sonuçlara göre, ifadelerin birbirleri ile uyumlu $(\alpha=0,922)$ oldukları görülmektedir (Tablo 1$)$. Ölçekte yer alan ifadelerin teker teker silinmesi sonucunda hesaplanan Cronbach Alfa değerleri, ölçeğin tamamı için hesaplanan değerden küçük, aynı zamanda ölçekteki ifadelerin hepsinin ifade toplam korelasyon kritik değeri 0,30'dan büyüktür. Bu sonuçlar, Covid-19 Korku Ölçeğinin çok güvenilir olduğunu göstermektedir (Nakip, 2013: 205).

Tablo 1. Geçerlilik ve Güvenirlik Analizleri Sonuçları

\begin{tabular}{|c|c|c|c|c|c|c|}
\hline Ölçek & $\begin{array}{l}\text { Iffade } \\
\text { No }\end{array}$ & N & Faktör Yükü & $\begin{array}{c}\text { Madde Toplam } \\
\text { Korelasyonu }\end{array}$ & $\begin{array}{l}\text { Cronbach's Alpha } \\
\text { (Madde Silinirse) }\end{array}$ & $\begin{array}{l}\text { Cronbach's } \\
\text { Alfa Değeri }\end{array}$ \\
\hline \multirow{7}{*}{ 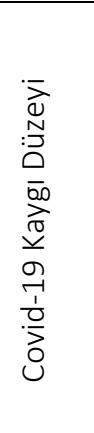 } & CK1 & 125 & 0,794 & 0,7298 & 0,9130 & \multirow{7}{*}{0,9220} \\
\hline & $\mathrm{CK} 2$ & 125 & 0,813 & 0,7499 & 0,9110 & \\
\hline & CK3 & 125 & 0,807 & 0,7259 & 0,9143 & \\
\hline & CK4 & 125 & 0,867 & 0,8123 & 0,9046 & \\
\hline & CK5 & 125 & 0,842 & 0,7794 & 0,9084 & \\
\hline & CK6 & 125 & 0,855 & 0,7856 & 0,9084 & \\
\hline & CK7 & 125 & 0,822 & 0,7438 & 0,9115 & \\
\hline
\end{tabular}

\section{Bulgular}

Araştırmaya katılan özel güvenlik personellerinin cinsiyetlerine ve medeni durumlarına ilişkin bilgiler Tablo 2'de gösterilmektedir. Tablo 2'deki sonuçlara göre, araştırma katılımcılarının \%32'sini oluşturan 40 kişi bekâr, araştırma katılımcılarının \%68'ini oluşturan 85 kişi evlidir. Ayrıca 88 erkek özel güvenlik personeli toplam katıımcıların \%70,40'ını, 37 kadın özel güvenlik personeli toplam katıımcıların \%29,60'ını oluşturmaktadır.

Tablo 2. Katılımcıların Demografik Özellikleri

\begin{tabular}{llcc}
\hline Demografik Özellik & & Sıklık & Yüzde \\
\hline \multirow{2}{*}{ Medeni Durum } & Bekar & 40 & 32,0 \\
& Evli & 85 & 68,0 \\
\hline \multirow{2}{*}{ Cinsiyet } & Erkek & 88 & 70,4 \\
& Kadın & 37 & 29,6 \\
\hline & Toplam & 125 & 100,0
\end{tabular}


Araştırma katılımcılarının Covid-19 geçmişlerine yönelik sorulara vermiş oldukları cevaplar Tablo 3'de gösterilmektedir. Araştırma katıımcılarının \%44,0'ü (55 kişi) daha önce Covid-19 testi yaptırmış, \%56,0'sı (70 kişi) ise yaptırmamıştır. Daha önce kendisine Covid-19 tanısı konan katılımcı oranı \%12,80 (16 kişi) iken, daha önce kendisine Covid-19 tanısı konmayan katılımcı oranı \%87,20 (109 kişi)'dir. Araştırma katııımcılardan \%88,0'inin (110 kişi) Covid-19 tanısı konan bir tanıdığı veya yakını varken, \%12'sinin (15 kişi) Covid-19 tanısı konan bir tanıdığı veya yakını yoktur. Araştırma katıımcılarından Covid-19 nedeni ile bir yakınını veya tanıdığını kaybedenlerin oranı \%58,40 (73 kişi) iken Covid-19 nedeni ile herhangi bir yakınını veya tanıdığını kaybetmeyenlerin oranı \%41,60 (52 kişi)'dır.

Tablo 3. Katılımcıların Covid-19 Geçmişine İlişkin Bilgiler

\begin{tabular}{llcc}
\hline Genel Bilgiler & & Sıkık & Yüzde \\
\hline Covid-19 testi yaptırdınız mı? & Evet & 55 & 44,0 \\
& Hayır & 70 & 56,0 \\
\hline $\begin{array}{l}\text { Covid-19 tanısı daha önce size } \\
\text { kondu mu? }\end{array}$ & Evet & 16 & 12,8 \\
\hline Covid-19 tanısı konan bir & Hayır & 109 & 87,2 \\
tanıdığınız/yakınınız oldu mu? & Evet & 110 & 88,0 \\
\hline Covid-19 nedeni ile bir & Hayır & 15 & 12,0 \\
$\begin{array}{l}\text { yakınınızı/tanıdığınızı kaybettiniz } \\
\text { mi? }\end{array}$ & Evet & 73 & 58,4 \\
\hline & Hayır & 52 & 41,6 \\
\hline
\end{tabular}

Araştırma katıımcılarının Covid-19 kaygı düzeyi ortalaması ve Covid-19 kaygı düzeyini belirlemeye yönelik kullanılan ölçekte yer alan 7 ifadenin ortalamaları Tablo 4'de gösterilmektedir. Covid-19 kaygı düzeyinin yorumlanması yapılırken; 1,00-1,79 arası çok düşük, 1,80-2,59 arası düşük, 2,60-3,39 arası orta, 3,40-4,19 arası yüksek ve 4,20-5,00 arası çok yüksek olarak dikkate alınmıştır (Özdamar, 2003: 32). Tablo 4'deki sonuçlar, araştırma katılımcılarının Covid-19 kaygı düzeyinin orta düzeyde $(2,80)$ olduğunu ortaya koymaktadır. Bu sonuçlara göre, ölçekte yer alan ifadelerinin ortalamaları 2,05 ile 3,38 arasında değişiklik göstermektedir. Araştırma katıımcılarının vermiş olduğu cevaplara göre, CK2 nolu "Covid-19'u düşünmek beni rahatsız eder" en yüksek ortalamaya $(3,38)$ sahip ifade iken, CK3 nolu "Covid-19'u düşündüğümde ellerim terler" en düşük ortalamaya $(2,05)$ sahip ifadedir.

Tablo 4. Tanımlayıcı İstatistikler

\begin{tabular}{llrrr}
\hline $\begin{array}{c}\text { Ifade } \\
\text { No }\end{array}$ & \multicolumn{1}{c}{ ifade } & N & Ortalama & $\begin{array}{c}\text { Std. } \\
\text { Sapma }\end{array}$ \\
\hline \multicolumn{2}{l}{ Genel Covid-19 Kaygı Düzeyi } & 125 & 2,80 & 1,01 \\
CK1 $\quad$ Covid-19'dan çok korkuyorum. & 125 & 3,34 & 1,23 \\
CK2 Covid-19'u düşünmek beni rahatsı eder. & 125 & 3,38 & 1,27 \\
CK3 Covid-19'u düşündüğümde ellerim terler. & 125 & 2,05 & 1,00 \\
CK4 Covid-19 yüzünden hayatımı kaybetmekten korkuyorum. & 125 & 3,01 & 1,36
\end{tabular}


CK5

Sosyal medyada Covid-19 ile ilgili haberleri ve hikâyeleri izlediğimde

gergin veya endişeli olurum.

CK6 Covid-19'a yakalanmaktan endişelendiğim için uyuyamıyorum.

Covid-19'a yakalandığımı düşündüğümde kalbim hızlanır veya çarpıntı yaşarım.
125

3,21

1,36

125

2,14

1,07

125

2,46

1,20

Covid-19 geçmişlerine ve demografik özelliklerine göre özel güvenlik personellerinin Covid-19 kaygı düzeyinde farklılaşma olup olmadığı "Bağımsız Gruplar T-Testi" ile incelenmiştir. "Bağımsız Gruplar T-Testi" analizi sonuçları Tablo 5'de gösterilmektedir.

Erkek özel güvenlik personellerinin Covid-19 kaygı düzeyi ile kadın özel güvenlik personellerinin Covid19 kaygı düzeyi arasında anlamlı bir farklıık bulunmaktadır ( $t=-2,1278, p<0,05)$. Kadın özel güvenlik personellerinin Covid-19 kaygı düzeyi erkek özel güvenlik personellerine göre daha yüksektir. Bu sonuç, Covid19 kaygı düzeyi üzerinde cinsiyetin orta düzeyde (Cohen $d=0,384$ ) etkisi olduğunu göstermektedir. Bu durumda "Özel güvenlik personellerinin Covid-19 kaygı düzeyi cinsiyete göre farklılaşmaktadır" şeklinde oluşturulan $\mathrm{H} 1$ hipotezi kabul edilmiştir.

Bekâr özel güvenlik personellerinin Covid-19 kaygı düzeyi ile evli özel güvenlik personellerinin Covid19 kaygı düzeyi arasında anlamlı bir farklılık bulunmaktadır ( $t=-2,1083, p<0,05)$. Evli özel güvenlik personellerinin Covid-19 kaygı düzeyi bekâr özel güvenlik personellerine göre daha yüksektir. Bu sonuç, Covid19 kaygı düzeyi üzerinde medeni durumun orta düzeyde (Cohen $d=0,380$ ) etkisi olduğunu ortaya koymaktadır. Bu durumda "Özel güvenlik personellerinin Covid-19 kaygı düzeyi medeni duruma göre farklılaşmaktadır" şeklinde oluşturulan $\mathrm{H} 2$ hipotezi kabul edilmiştir.

Daha önce kendisine Covid-19 tanısı konan ve konmayan özel güvenlik personelleri arasında farklılık olup olmadığını belirlemeye yönelik sorulan "Covid-19 tanısı size daha önce kondu mu?" sorusuna "Evet" cevabı verenler ile "Hayır" cevabı verenler arasında anlamlı bir farklılık bulunmaktadır ( $t=2,6747, p<0.05)$. Daha önce kendisine Covid-19 tanısı konan özel güvenlik personellerinin, daha önce kendisine Covid-19 tanısı konmayan özel güvenlik personellerine göre Covid-19 kaygı düzeyi daha yüksektir. Bu sonuca göre, daha önce bireye Covid-19 tanısı konulup konulmamasının Covid-19 kaygı düzeyi üzerinde orta düzeyde (Cohen $\mathrm{d}=0,482$ ) etkisi olduğu görülmektedir. Bu durumda "Özel güvenlik personellerinin Covid-19 kaygı düzeyi daha önce kendilerine Covid-19 tanısı konup konmadığına göre farklılaşmaktadır" şeklinde oluşturulan H4 hipotezi kabul edilmiştir.

Tablo 5. Bağımsız Gruplar T-Testi Analizi Sonuçları

\begin{tabular}{|c|c|c|c|c|c|c|c|c|}
\hline & Kategori & $\mathrm{N}$ & Ortalama & $\begin{array}{c}\text { Std. } \\
\text { Sapma }\end{array}$ & t & sd & $p$ & Cohen d \\
\hline \multirow{3}{*}{ Cinsiyet } & Erkek & 88 & 2,6753 & 1,0054 & \multirow{3}{*}{$-2,1278$} & \multirow{3}{*}{123} & \multirow{3}{*}{$0,035^{*}$} & \multirow{3}{*}{0,384} \\
\hline & & & & & & & & \\
\hline & Kadın & 37 & 3,0888 & 0,9579 & & & & \\
\hline \multirow{2}{*}{ Medeni Durum } & Bekar & 40 & 2,5250 & 0,9317 & \multirow{2}{*}{$-2,1083$} & \multirow{2}{*}{123} & \multirow{2}{*}{$0,037^{*}$} & \multirow{2}{*}{0,380} \\
\hline & Evli & 85 & 29261 & 1,0189 & & & & \\
\hline \multirow{3}{*}{ Covid-19 testi yaptırdınız mı? } & Evet & 55 & 2,8649 & 0,9446 & \multirow{3}{*}{0,6608} & \multirow{3}{*}{123} & \multirow{3}{*}{0,510} & \\
\hline & & & & & & & & \\
\hline & Hayır & 70 & 2,7449 & 1,0551 & & & & \\
\hline \multirow{2}{*}{$\begin{array}{l}\text { Covid-19 tanısı daha önce size } \\
\text { kondu mu? }\end{array}$} & Evet & 16 & 3,4107 & 0,7093 & \multirow{2}{*}{2,6747} & \multirow{2}{*}{123} & \multirow{2}{*}{$0,009 * *$} & \multirow{2}{*}{0,482} \\
\hline & Hayır & 109 & 2,7077 & 1,0138 & & & & \\
\hline
\end{tabular}




\begin{tabular}{|c|c|c|c|c|c|c|c|}
\hline \multirow{3}{*}{$\begin{array}{l}\text { Covid-19 tanısı konan bir } \\
\text { tanıdığınız/yakınınız oldu mu? }\end{array}$} & & & & & \multirow{3}{*}{$-0,6334$} & \multirow{3}{*}{123} & \multirow{3}{*}{0,528} \\
\hline & Evet & 110 & 2,7766 & 0,9870 & & & \\
\hline & Hayır & 15 & 2,9524 & 1,1602 & & & \\
\hline \multirow{2}{*}{$\begin{array}{l}\text { Covid-19 nedeni ile bir } \\
\text { yakınınızı/tanıdığınızı kaybettiniz mi? }\end{array}$} & Evet & 73 & 2,7847 & 0,9280 & \multirow{2}{*}{$-0,1703$} & \multirow{2}{*}{123} & \multirow{2}{*}{0,865} \\
\hline & Hayır & 52 & 2,8159 & 1,1150 & & & \\
\hline
\end{tabular}

* $p<0,05$ düzeyinde; ${ }^{* *} p<0,01$ düzeyinde anlamlıdır.

Tablo 5'de gösterilmekte olan analiz sonuçlarına göre; özel güvenlik personellerinin daha önce Covid19 testi yaptırıp yaptırmamaları, daha önce bir tanıdığına veya yakınına Covid-19 tanısı konulup konulmaması ve daha önce bir tanıdığını veya yakınını Covid-19 nedeni ile kaybedip kaybetmemesine göre Covid-19 kaygı düzeylerinde her hangi bir anlamlı farklılık olmadığı tespit edilmiştir. Bu sonuca göre; H3, H5 ve H6 hipotezleri ret edilmiştir.

\section{Sonuç ve Tartışma}

Covid-19 pandemisi sürecinde yüksek risk ve tehlike altında çalışan özel güvenlik personellerinin Covid19 kaygı düzeyinin Covid-19 geçmişlerine ve demografik özelliklerine göre farklılaşıp farklılaşmadığını tespit etmek amacı ile yapılan bu çalışmada, Hatay ilinde aktif olarak görev yapan 125 özel güvenlik personelinden elde edilen veriler ışı̆̆ında analizler yapılmıştır.

Araştırma sonuçları özel güvenlik personellerinin Covid-19 kaygı düzeyinin orta seviyede olduğu göstermektedir. Özel güvenlik sektörü zaten çok fazla stres ve risk içeren bir alan olması nedeni ile özel güvenlik personellerinin psikolojik olarak olağanüstü durumlara hazırlıkı olmaları Covid-19 kaygı düzeylerinin yüksek çıkmamasının bir nedeni olarak yorumlanabilir. Altun (2020) tarafından gerçekleştirilen Covid-19 pandemisinde kaygı durumu ile hijyen davranışları arasındaki ilişkinin incelendiği çalışmada bu araştırma ile benzer sonuçlara ulaşılmıştır. Altun (2020) çalışmasında bireylerin yüksek düzeyde Covid-19 kaygısı yaşamamasını; pandeminin kısmen kontrol altına alınması ve pandemi sürecine alışımasından kaynaklandığını belirtmektedir.

Araştırmanın dikkat çekici sonuçlarından birisi özel güvenlik personellerinin Covid-19 kaygı düzeyini ölçmek için kullanılan ölçekte yer alan ifadelerden hangilerinin ortalamasının yüksek olduğu, hangilerinin ise düşük olduğu ile ilgilidir. Ölçek ifadelerinden en yüksek ortalama sırası ile "Covid-19'u düşünmek beni rahatsız eder", Covid-19'dan çok korkuyorum" ve "Sosyal medyada Covid-19 ile ilgili haberleri ve hikâyeleri izlediğimde gergin veya endişeli olurum" ifadeleridir. Diğer taraftan ölçekteki ifadelerden en düşük ortalama sırası ile "Covid-19'u düşündüğümde ellerim terler", "Covid-19'a yakalanmaktan endişelendiğim için uyuyamıyorum" ve "Covid-19'a yakalandığımı düşündüğümde kalbim hızlanır veya çarpıntı yaşarım" ifadeleridir. Bu sonuca göre, Covid-19 kaygısı daha çok rahatsız olma, korkma ve gergin veya endişeli olma gibi psikolojik durumlar şeklinde ortaya çıkarken, nispeten daha az ellerin terlemesi, uykusuzluk ve kalp sorunları gibi fiziksel durumlar şeklinde ortaya çıkmaktadır.

Araştırma sonuçları, cinsiyet, medeni durum ve daha önce kendisine Covid-19 tanısı konulup konulmadığına göre özel güvenlik personellerinin Covid-19 kaygı düzeyinde farklılaşma olduğunu göstermektedir. Kadın özel güvenlik personellerinin Covid-19 kaygı düzeyi erkek özel güvenlik personellerine göre daha yüksektir. Bu sonuç, Covid-19 kaygısı ile ilgili yapılan birçok araştırmanın (Altun, 2020; Gümüşgül vd., 2020; Lai vd., 2020; Wang vd., 2020; Arpacıoğlu vd., 2021) sonucu ile paralellik göstermektedir. Wang, vd. (2020) göre, kadınlar üzerinde Covid-19 pandemisinin psikolojik etkileri daha büyüktür. Lai vd. (2020) tarafından yapılan araştırmada, kadınların daha yüksek kaygı belirtileri gösterdiği ifade edilmektedir. Arpacıoğlu vd., (2021) tarafından sağlık çalışanlarının Covid-19 korkusu üzerine yapılan araştırma sonuçları da benzer şekilde, kadın sağlık çalışanlarının korku ve kaygı düzeylerinin erkek sağlık çalışanlara göre daha yüksek olduğunu göstermektedir. Bu sonuçlara göre; kadın çalışanların aile içerisindeki rollerinden ve sorumluluklarından kaynaklı olarak Covid-19'dan daha fazla kaygı duydukları söylenebilir.

Araştırma sonuçlarına göre, evli özel güvenlik personellerinin Covid-19 kaygı düzeyi bekâr özel güvenlik personellerine göre daha yüksektir. Evli bireyler ile bekâr bireyler arasında anlamlı bir farkın ortaya çıkması, bireylerin kendilerinden çok aslında eşleri ve çocukları olmak üzere aile bireylerine hastalığın bulaşmasından 
korktuğu şeklinde yorumlanabilir. Arpacıoğlu vd. (2021) tarafından yapılan araştırma sonuçları, bu araştırmanın sonucu desteklemektedir. Arpacıoğlu vd. (2021) çalışmalarında, eşi ve çocukları ile yaşayan bireylerin yalnız yaşayanlara oranla Covid-19 kaygı düzeyinin daha yüksek olduğunu ifade etmektedir.

Daha önce kendisine Covid-19 tanısı konan özel güvenlik personellerinin, daha önce kendisine Covid19 tanısı konmayan özel güvenlik personellerine göre Covid-19 kaygı düzeyi daha yüksektir. Hastalığa yakalanan bireyler tedavi sürecinin zorluğu, tedavi öncesi ve sonrası yaşadıkları deneyimler ve sağık kurumlarında gözlemleme fırsatı buldukları diğer hastaların durumları gibi farklı nedenlerden dolayı hastalık ile ilgili daha fazla farkındalığa sahiptir. Bu durum onların hastalığa olan bakış açııını değiştirmiş olabilir.

Bu çalışmada, Covid-19 kaygı düzeyi demografik özellikler ve Covid-19 geçmişi açısından ele alınmıştır. Illeriki çalışmalarda kişilik özellikleri gibi bireysel ve örgüt iklimi gibi örgütsel unsurlar açısından Covid-19 kaygı düzeyinin incelenmesi faydalı olabilir. Ayrıca farklı meslek gruplarında Covid-19 kaygısına ilişkin yapılacak olan çalışmalar, ulaşılan sonuçların genelleştirilmesine katkı sağlayabilir.

\section{Kaynakça}

Ahmed, M.Z., Ahmed, O., Aibao, Z., Hanbin, S., Siyu, L. ve Ahmad, A. (2020). Epidemic of COVID-19 in China and associated psychological problems. Asian Journal of Psychiatry, 51, 1-7. https://doi.org/10.1016/j.ajp.2020.102092

Ahorsu, D.K., Lin, C.Y., Imani, V., Saffari, M., Griffiths, M. D. ve Pakpour, A.H. (2020). The fear of COVID-19 scale: Development and initial validation. International Journal of Mental Health and Addiction, 1-9. https://doi.org/10.1007/s11469-020-00270-8

Akalın, B. ve Modanlıoğlu, A. (2021). Covid-19 sürecinde yoğun bakımda çalışan sağlık profesyonellerinin duygu-durum ve tükenmişlik düzeylerinin değerlendirilmesi. Acıbadem Üniversitesi Sağlık Bilimleri Dergisi, $12(2), 346-352$.

Akbaba, A.N.B. ve Bulut, N. (2021). Pandemi Sürecinde Muhasebe Meslek Mensuplarının Mesleki Tükenmişlik Düzeylerinin İncelenmesi. European Journal of Managerial Research (EUJMR), 5(Özel), 35-48.

Altun, Y. (2020). Covid-19 pandemisinde kaygı durumu ve hijyen davranışları. Sürekli Tıp Eğitimi Dergisi, 29(5), 312-317.

Arpacıoğlu, S., Baltalı, Z. ve Ünübol, B. (2021). COVID-19 pandemisinde sağlık çalışanlarında tükenmişlik, Covid korkusu, depresyon, mesleki doyum düzeyleri ve ilişkili faktörler. Cukurova Medical Journal, 46(1), 88100.

Cnnturk. (2020). Son Dakika: Hastanenin Güvenlik Görevlisine Çirkin Saldırı. Erişim Tarihi:31.03.2021, https://www.cnnturk.com/turkiye/hastanenin-guvenlik-gorevlisine-cirkin-saldiri

Dinibutun, S.R. (2020). Factors associated with burnout among physicians: An evaluation during a period of COVID-19 pandemic. Journal of Healthcare Leadership, 12, 85-94.

Ersezgin, R. ve Sevi Tok, E.S. (2019). "Algılanan iş stresi, psikolojik dayanıklılık, başa çıkma stilleri ve özduyarlııı̆ın tükenmişlik düzeyini yordayıcı etkisi". Uludağ Üniversitesi Fen-Edebiyat Fakültesi Sosyal Bilimler Dergisi, 20, 1-36.

Gümüşgül, C., Ersoy, A. ve Gümüşgül, O. (2020). Amatör ve profesyonel sporcuların yeni tip koronavirüse (Covid-19) yakalanma kaygılarının incelenmesi-Yönetsel karar boyutu. Sportif Bakış: Spor ve Eğitim Bilimleri Dergisi, 7(1), 26-37.

Ho, C.S.H., Chee, C.Y.I. ve Ho, R.C.M. (2020). Mental health strategies to combat the psychological impact of COVID-19 beyond paranoia and panic. Annals, Academy of Medicine, 49(1), 1-6.

Ladikli, N., Bahadır, E., Yumuşak, F.N., Akkuzu, H., Karaman, G. ve Türkkan, Z. (2020). Kovid-19 korkusu ölçeği'nin Türkçe güvenirlik ve geçerlik çalışması. International Journal of Social Science, 3(2), 71-80.

Lai, J., Ma, S., Wang, Y. ve ark. (2020). Factors associated with mental health outcomes among health care workers exposed to Coronavirus disease 2019. JAMA Network Open 2020, 3(3), 1-12. 
Moccia, L., Janiri, D., Pepe, M., Dattoli, L., Molinaro, M., De Martin, V., Chieffo, D., Janiri, L., Fiorillo, A., Sani, G. ve Di Nicola, M. (2020). Affective temperament, attachment style, and the psychological impact of the COVID-19 outbreak: An early report on the Italian general population. Brain, Behavior, and Immunity, 87, 75-79. https://doi.org/10.1016/j.bbi.2020.04.048

Nakip, M. (2013). Pazarlamada Araştırma Teknikleri. Ankara: Seçkin Yayıncılık.

Özdamar, K. (2003). Modern bilimsel araştırma yöntemleri: araştırma planlama, toplum ve örnek seçimi, güç analizi, proje hazırlama, veri toplama, veri analizi, bilimsel rapor yazımı. Eskişehir: Kaan Kitabevi.

Sabah. (2020). Son Dakika: Coronavirüsün En Çok Öldürdüğü Meslekler Açıklandı! Kadınlar ve Erkekler İçin Farklı Tablolar. Erişim Tarihi:31.03.2021, https://www.sabah.com.tr/dunya/2020/06/29/son-dakikacoronavirusun-en-cok-oldurdugu-meslekler-aciklandi-kadinlar-ve-erkekler-icin-farkli-tablolar.

SB. (2021). Türkiye Covid-19 Hasta Tablosu. Erişim Tarihi:31.05.2021, https://covid19.saglik.gov.tr/

Sputniknews. (2020). Koronavirüs Şüphelisi Hastanenin Güvenlik Görevlilerine Saldırdı: Bende Varsa Herkese Bulaşsın. Erişim Tarihi:31.03.2021, https://tr.sputniknews.com/turkiye/202004151041833141

TDK. (2021). Erişim Tarihi: 20.03.2021, https://sozluk.gov.tr/

Uçkun, C.G. ve Uçkun, S. (2020). Pandemide özel güvenlik görevlilerinin rolü ve önemi. TURAN: Stratejik Arastirmalar Merkezi, 12(47), 189-191.

Wang, C., Pan, R., Wan, X., Tan, Y., Xu, L., Ho, C.S. ve Ho, R.C. (2020). Immediate psychological responses and associated factors during the initial stage of the 2019 Coronavirus Disease (COVID19) epidemic among the general population in China. International Journal of Environmental Research and Public Health, 17(5), 1-25. https://doi.org/10.3390/ijerph17051729

WHO. (2021). WHO Coronavirus (COVID-19) Dashboard. Erişim Tarihi:01.06.2021, https://covid19.who.int/

Yüncü, V. ve Yılan, Y. (2020) COVID-19 pandemisinin sağlık çalışanlarına etkilerinin incelenmesi: Bir durum analizi. Iğdır Üniversitesi Sosyal Bilimler Dergisi, Ekim, 373-401.

\section{Structured Abstract}

\section{Introduction}

Covid-19 anxiety, which arises from the fear of contracting the disease, the fear of not being able to be treated due to the insufficient capacity of health institutions, and the fear of infecting the family and the environment, can have different psychological effects on private security guards as well as all employees. Determining the factors affecting the Covid-19 anxiety levels of private security guards is a great importance both for the protection of individuals' psychological and physiological health and for the creation of a positive organizational climate. Therefore, "What are the demographic characteristics that affect Covid-19 anxiety?" and "How does the Covid-19 background of individuals shape Covid-19 anxiety?" These are two important questions that need to be answered. In order to find answers to these questions, the following hypotheses have been developed to determine whether the Covid-19 anxiety levels of private security guards differ according to their Covid-19 backgrounds and demographic characteristics.

H1. "Covid-19 anxiety level of private security guards differs according to gender"

H2. "Covid-19 anxiety level of private security guards differs according to marital status"

H3. "Covid-19 anxiety level of private security guards differs according to whether they have had the Covid-19 test before or not"

H4. "Covid-19 anxiety level of private security guards differs according to whether they have been diagnosed with Covid-19 before"

H5. "Covid-19 anxiety level of private security guards differs according to whether an acquaintance or relative of the private security guard has been diagnosed with Covid-19 before"

H6. "Covid-19 anxiety level of private security guards differs according to whether the private security guard lost an acquaintance or relative due to Covid-19 before"

\section{Materials and Methods}


The aim of this study; it is to determine whether the Covid-19 anxiety level of private security guards differs according to their Covid-19 background and demographic characteristics. For this purpose, private security guards who work actively in the province of Hatay were determined as the universe of the research and data were collected from 125 guards by online survey technique. In order to determine the Covid-19 anxiety level used to "The Fear of Covid-19 Scale" that was developed by Ahorsu et. al (2020). Whether there is a differentiation in the Covid-19 anxiety level according to Covid-19 background and demographic characteristics of guards was analyzed with the "Independent Groups T-Test".

\section{Results}

The results of the analysis reveal that the Covid-19 anxiety level of the participants is moderate (2.80). The averages of the expressions in the scale vary between 2.05 and 3.38. According to the answers given by the participants, the expression CK2 "It makes me uncomfortable to think about Covid-19" has the highest average (3.38), while the expression CK3 "My hands become clammy when I think about Covid-19" has the lowest average (2.05).

There is a significant difference between the Covid-19 anxiety level of male private security guards and the Covid-19 anxiety level of female private security guards ( $t=-2.1278, p<0.05)$. The Covid-19 anxiety level of female private security guards are higher than that of male private security guards. This result shows that gender has a moderate (Cohen $\mathrm{d}=0.384$ ) effect on Covid-19 anxiety level. In this case, the H1 hypothesis, which was created as "Covid-19 anxiety level of private security guards differs according to gender", was accepted.

There is a significant difference between the Covid-19 anxiety level of single private security guards and the Covid-19 anxiety level of married private security guards $(t=-2,1083, p<0.05)$. The Covid-19 anxiety level of married private security guards are higher than that of single private security personnel. This result reveals that marital status has a moderate (Cohen $d=0.380$ ) effect on Covid-19 anxiety level. In this case, the $\mathrm{H} 2$ hypothesis, which was created as "Covid-19 anxiety level of private security guards differs according to marital status", was accepted.

When asked to determine whether there is a difference between private security guards who were previously diagnosed with Covid-19 and those who were not, "Have you been diagnosed with Covid-19 before?" There is a significant difference between those who answered "Yes" to the question and those who answered "No" ( $t=2.6747, p<0.05)$. Private security guards who were previously diagnosed with Covid-19 have a higher Covid-19 anxiety level than private security guards who have not been diagnosed with Covid-19 before. According to this result, it is seen that whether an individual has been diagnosed with Covid-19 before has a moderate (Cohen $\mathrm{d}=0.482$ ) effect on the Covid-19 anxiety level. In this case, the H4 hypothesis, which was created as "Covid-19 anxiety level of private security guards differs according to whether they have been diagnosed with Covid-19 before," was accepted.

According to the results of the analysis, it has been determined that there is no significant difference according to whether the private security guards have had the Covid-19 test before or not; whether an acquaintance or relative of the private security guard has been diagnosed with Covid-19 before and whether the private security guard lost an acquaintance or relative due to Covid-19 before. According to these results; Hypotheses $\mathrm{H} 3, \mathrm{H} 5$ and $\mathrm{H} 6$ were rejected.

\section{Conclusion}

In this study, it was concluded that there is a significant difference in the level of Covid-19 anxiety according to gender, marital status and whether the person has been diagnosed with Covid-19 before. The results of the research show that the Covid-19 anxiety level of females are higher than males. Besides, the analysis results show that married guards have a higher Covid-19 anxiety level than single guards. In addition, the results of the research reveal that the level of Covid-19 anxiety is higher for guards who have been diagnosed with Covid-19, compared to guards who have not been. On the other hand, it has been determined that there is no significant difference in Covid-19 anxiety levels, depending on whether guards have had a Covid-19 test, their relative has been diagnosed with Covid-19, and they have lost a relative due to Covid-19. 
It is thought that this study will make an important contribution to the literature in determining the factors affecting the Covid-19 anxiety level of employees. In addition, this study is the first to examine the Covid-19 anxiety level of private security guards. This gives originality to this study. 